\title{
Vaginal Fibromyoma- A Case Report
}

\author{
Loi TT ${ }^{1 *}$ and Chau BTV ${ }^{2}$ \\ ${ }^{1} O B / G Y N$ Department, Vietnam National University, Vietnam \\ ${ }^{2}$ University of Medicine and Pharmacy, Vietnam
}

Submission: November 16, 2017; Published: November 27, 2017

*Corresponding author: Loi TT, OB/GYN Department, School of Medicine, Vietnam National University, Vietnam, Email: tranthiloi@hotmail.com

\begin{abstract}
Summary
Vaginal fibromyoma (leiomyoma) is a very rare benign tumor of vagina, and may be misdiagnosed. Until now, there is approximately 300 cases have been reported in the literature. We report the case of a 43 year-old woman G2 P1 came from a province hospital with chief complaints of dysuria and pelvic pressure. There, she was misdiagnosed having uterine fibromyoma and was operated but the uterus was normal. The patient was transferred to a tertiary hospital, Tu Du Gyneco-Obstetrics Hospital at Ho Chi Minh City, Vietnam. Thanks to careful pelvic examination, ultrasound and magnetic resonance imaging (MRI) a firm, non-tender mass, measuring about $82 \times 70 \times 68 \mathrm{~mm}$ in the anterior vaginal wall was revealed. A complete surgical excision through the vaginal route was performed, and the histopathology report confirmed the diagnosis of benign leiomyoma.
\end{abstract}

Keywords: Vaginal fibromyoma; Benign leiomyoma

\section{Introduction}

Vaginal fibromyomas are very rare benign tumors of vagina, until now, there are approximately 300 cases have been reported in the literature [1]. Depending on its size and location, this tumor may cause varied clinical signs: dyspareunia, pain, pelvic pressure, dysuria. Leiomyoma of the vagina may be misdiagnosed as uterine leiomyoma, paraurethral mass, cystocele. Vaginal fibromyomas may appear alone or associated with myomas elsewhere such as uterine fibromyoma. Here, we are reporting a case of primary vaginal fibromyoma misdiagnosed as uterine fibromyoma.

\section{Case Report}

A 43 year-old woman gravida 2 para 1 came to a province hospital with chief complaints of dysuria and having a sensation of pelvic pressure. She has normal menstruation, no history of dysmenorrhea. There, because of misdiagnosis of having a big uterine fibromyoma, she was operated. On laparotomy, the uterus and two annexes were completely normal, the surgeons closed the abdomen. One month later, she was transferred to $\mathrm{Tu} \mathrm{Du}$ Gyneco-Obstetrics Hospital in HCM C, a tertiary hospital. Here, thanks to careful pelvic examination, ultrasound and magnetic resonance imaging (MRI) we revealed a firm, non-tender mass, measuring about $82 \times 70 \times 68 \mathrm{~mm}$ in the anterior extend to right side of vaginal wall. We decide to choose vaginal route to perform surgical excision of the tumor. The patient was catheterized to protect the bladder. Under spinal anesthesia, a transverse incision was done to enucleate the tumor. This myoma was big, so we had to morcellate it into many small pieces to avoid injury to the bladder. The vagina was repaired by single layer closure procedure with drainage and tamponade the vagina by gauze for hemostasis

In one day the drainage and tamponade were removed and the patient was discharge in 3 days postoperated. The histopathology report confirmed the diagnosis of benign leiomyoma.

\section{Discussion}

Leiomyomas are common benign tumors in the uterus, but they are rarely seen in the vagina. Since 1733 when Denys de Leyden detected the first case of vaginal fibromyoma until now, there were about 300 cases reported in the literature [2]. Most of patients are in reproductive age, average age: 30-50 years old [3]. Vaginal fibromyomas commonly occur on the anterior vaginal wall with the dimension change from 0.5 to $15 \mathrm{~cm}[4]$. Small vaginal fibromyoma may be misdiagnosed as urethral diverticulum or paraurethral cyst, while the big one may be 
misdiagnosed as uterine myoma. Preoperative diagnosis has to be performed very carefully with pelvic examination, ultrasound and MRI to avoid misdiagnosis and mistreatment.

Excision through a vaginal approach is generally indicated [5]. This is usually easy but can be very difficult if the tumor is large, vascular and extending into the broad ligament. In the later case, a laparotomy is preferred because the procedure may be very complicated.

So when we find outa mass in the vagina in pelvic examination, we should keep in mind the diagnosis of one very rare tumor: vaginal fibromyoma to avoid misdiagnosis and mistreatment.

\section{References}

1. Young SB, Rose PG, Reuter KL (1991) Vaginal fibromyomata: two cases with preoperative assessment, resection and reconstruction. Obstet Gynecol 78(5): 972-974.

2. Indranil C, Anuradha D, Shyamapada P (2011) Vaginal leiomyoma. J Midlife Health 2(1): 42-43.

3. Yu W, Weiming W, Xujun S, Liang K, Jun Q (2015) A misdiagnosed vaginal leiomyoma. Urol Case Rep 3(3): 82-83.

4. Sunita G, Prachi D, Madhuri G, Varsha K, Sheela J, et al. (2014) A rare case of vaginal leiomyoma. PJMS 4(2): 63-64.

5. Kavyashree G, Manohar R, Kala B (2014) Vaginal leiomyoma: unusual case presentation. Indian Journal of Clinical Practice 24(10): 968-969.

\section{Your next submission with Juniper Publishers will reach you the below assets}

- Quality Editorial service

- Swift Peer Review

- Reprints availability

- E-prints Service

- Manuscript Podcast for convenient understanding

- Global attainment for your research

- Manuscript accessibility in different formats

( Pdf, E-pub, Full Text, Audio)

- Unceasing customer service

Track the below URL for one-step submission https://juniperpublishers.com/online-submission.php 